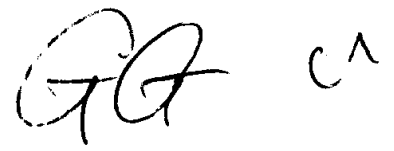

\title{
Information Superhighways - Does Europe Need Them, Can Europe Build Them?
}

\author{
David.O.Williams \\ Computing \& Networks Division \\ European Laboratory for Particle Physics (CERN) \\ 1211 Geneva 23 \\ Switzerland \\ (E.mail: David.O.Williams@cern.ch) \\ February 1994
}

A keynote talk at the HPCN Europe 1994 conference, Munich, April 1994

I was in a Printing-house in Hell, and saw the method in which knowledge is transmitted from generation to generation. - William Blake, The Marriage of Heaven and Hell.

\section{What is an Information Superhighway?}

When one reads in the International Herald Tribune (February 3, 1994) of a company set up in Beijing to create a Chinese information superhighway, it is clearly time to think about what we are doing in Europe. However, one must first establish whether an Information Superhighway is anything more than a buzzword or a gimmick.

It is certainly more than a buzzword. Over the last two years it has become clear that networking is coming of age, and is in the process of escaping from the small world of academia and research into the big brash world of commerce and business. This is because it offers economic opportunities, including cheap access to valuable information. Also, for the first time, teleconferencing over a universal network is starting to offer an alternative to the expensive and polluting transport of people to meetings.

The Internet, which I am using here very loosely to mean the interconnected set of all the world's networks, has been growing phenomenally in recent years. From its origins in the research community in the 1970s (ARPAnet etc.) it has spread via high-tech research companies, and then through tentative use by the general business and commerical worlds. For at least the last two years the concept of the Internet, somewhat generalised, and with its name evolved to the Information Superhighway, has been seen in the USA as a straight commercial opportunity to make money. Some European companies are now starting to wonder if they are missing out on what is happening in this field.

The present Internet now spans the world and has a blend of commercial and academic users. With a local area network and a medium speed connection (say $1 \mathrm{Mbit} / \mathrm{s}$ ) a user with a workstation or high-end personal computer can today access remarkable quantities of information including drawings and images as well as text in multiple fonts. Even with low speed modem connections (typically $9.6 \mathrm{Kbit} / \mathrm{s}$ ) anybody with a personal computer can access fantastic quantities of text information either on the (TCP/IP) Internet [1] or on commercial services such as CompuServe. The latter has in fact grown from a pure text bulletin board system to become a supplier of several useful services which are billed via the subscriber's credit card on a monthly basis.

The fastest growing information service on the Internet today is the WorldWideWeb [2] which originated at CERN for the particle physics research community, but which is now in use at thousands of sites around the world. It offers simple and consistent access to a multitude of information stored on Web servers all around the world and, above all, without requiring the user to $\log$ on to those distant information servers. In a few seconds one can find colour images from the repaired Hubble Space Telescope, a paper on the proof of Fermat's last theorem, or information from the Deutches Klimarechenzentrum in Hamburg. During the preparation of this paper, one of my colleagues used the Web to consult economic data which is publically available from the Central Intelligence Agency (CIA) 
Fact Book. Web users are largely unaware of where the information they see is stored and how it reaches their screen. It should also be noted that although what the Web accesses is technically described as "data", it can in fact be any kind of information which can be visualised on a screen. Use of the Web grew by more than $300,000 \%$ during 1993. CERN is proud of the Web, but of course it is only a beginning. The Web cannot deliver moving pictures or sound yet, but this can only be a matter of time.

Thus the network can now give access to stored information in a way which, to some of its users, seems as revolutionary as the invention of the printing press. Technology is also close to the market which will allow access to human beings across the network as well: from the primitive mechanisms of electronic mail and conferences using a single text font, we are moving on to the era of multi-media electronic mail and desktop video-conferencing. Both of these technologies have been running as advanced pilot services on the Internet for some time, and one can expect them to emerge as fully interworking multi-vendor products in the near future.

However, even among the academics who already have access to multi-media electronic mail and desktop conferencing, these tools are surprisingly little used. They have not yet become a way of life like plain text electronic mail. In Europe at least, there is no mystery about the reason for this: we do not have enough bandwidth, because bandwidth is too expensive.

Let us for a moment investigate the consequences of assuming that cabling and bandwidth are free. The Internet would probably expand to provide universal service in the style of the telephone network, with several megabits per second into every home and several hundred megabits per second into and out of every enterprise. What could be done with that capacity? The most uninteresting new service (at least to me personally) is the one most widely discussed in the press, namely "video on demand." In this case a magic box attached to every television allows the customer to select and pay for any video which he or she can find in the menus offered by entertainment companies. This is so obviously possible that major contracts were signed last year between entertainment companies, cable TV companies, and systems houses to put such systems into the mass market in the USA. In this case the cabling and bandwidth are effectively free, since the cable TV companies have already installed them.

However, cable TV is normally a one-way (outbound from server to client) service. Only a few bauds are necessary to send back the customer's menu selections to the video server, and most cable TV systems allow for this. If we assume that the multi-megabit connections to the home are duplex connections, then every home computer (including the ones built into the television, the washing machine, the heating system, etc.) could have high speed Internet access. With this, homes, schools, businesses, and so on can use interactive services which are much more sophisticated than video on demand. As with all revolutionary technologies it is impossible to predict today the use that society will make tomorrow of access to an information superhighway. Just for fun, here are some possibilities for use of the superhighway from your house one Saturday moming:

- Retrieve a copy of your 1990 holiday video tapes from an archive server.

- Inspect a hotel room in Oslo, Florence or San Francisco before booking it.

- Book your seats for La Scala after inspecting the view of the stage that they provide.

- Listen to Der Spiegel for the third week of 1991, automatically translated into the language of your choice.

If bandwidth were free, and given how little computing power now costs, none of the above would be unrealistic in an affluent society. But is this idea of an information superhighway just a gimmick? The only answer to this is that the telephone and the car were certainly regarded as gimmicks when invented, and we know what they have done for society. An information superhighway could even begin to undo some of the damage done by the car.

\section{Does Europe Need Them?}

The title of this section begs the question of whether there should be one information superhighway, or many. In fact, as we have many roads, but one road network, it is probably a meaningless distinction: all information networks should be interconnected although some of them will be better or more expensive to use than others.

It has been common practice for many research scientists to use computer networks on a daily or hourly basis for many years. In recent years this way of collaborating with colleagues has become common throughout the academic 
community and also inside most major international companies (not only those in the computer business). Within the last two years the Internet has spread into the public domain, with schools, local and national governments (including the White House), and the media (including the BBC World Service) announcing their electronic mail addresses. By early 1994 it became common to encounter references to the Internet in the press or on radio or television.

However, most of this spectacular growth has concerned electronic mail at relatively low speeds, and with strong limitations on such things as accented characters or non-Latin alphabets (which is a very valid source of cultural concem outside the American- or English-speaking world). As mentioned above, modern network technology can do much more than treat simple text, and there will be strong opporunities for other cultures to benefit from the opportunities that are becoming available. Furthermore, scientific or engineering resources can be shared over continental distances. As computing power becomes progressively cheaper, the critical resource to be shared is no longer processor power but mass storage, or rather the contents of the mass store. Every industry or scientific discipline can provide examples. In high energy particle physics research, a grand challenge of the next decade will be the collaborative design of massive and enormously complex detectors for experiments at the Large Hadron Collider planned at CERN for the early years of the next century. Hundreds of engineers and physicists in many countries must collaborate in these design efforts. Unless they can share a design and simulation database containing millions of items, which is constantly up to date, the design will be wrong. Instant high speed network access is not a luxury for them; it is a basic necessity. So it will be for any Europe-wide scientific or engineering collaboration.

It is not by chance that the White House is on the Internet. Both Vice-President Gore and President Clinton have recognised the vital importance of computer networking for high-technology industry. In Europe, we are still years behind the USA in the political understanding of this issue and therefore in any relevant action, despite some progress in work and studies sponsored by the European Commission [3].

I have given elsewhere [4] a number of reasons why Europe, and European industry in particular, must not be left further behind in this race to benefit from high speed networks. Even without extending the network into every home, how can industry function efficiently on a European scale without a network? How can BMW and Rover efficiently share automobile design documents without linking their computer systems at top speed? How can Italian farmers benefit in good time from weather forecasts computed in England? How can aerospace designers share their simulations between workers in different countries? The original HPCN report [5] suggested that such issues may have a significant effect on GNP growth.

Europe has had a hard struggle to maintain the competitivity of its traditional manufacturing industries and it remains weak in many high technology industries. These areas are the ones that can benefit most from high performance, low delay networking to optimise their technical collaboration across the continent. Even if Europe does not succeed in creating an indigenous distributed computing industry, it would be suicidal for the rest of industry not to make the most of this technology.

It is less clear whether Europe should rush into the business of video on demand and the other potential mass-market information highway services. This is in a sense a social and political question before it is an economic one. The desirability of these services is not debated in the USA because the First Amendment to the Constitution makes it impossible to stop them anyway. In Europe this matter is not so clear and one can expect information services for the public to be treated like the broadcast media. We can expect extensive and continuing political debate about pornography, violence, parental guidance, local language content, etc. This was surely prefigured by a recent case in which the Canton of Vaud successfully prosecuted the Director-General of the Swiss PTT over his responsibilities in the provision of pornographic services over the public telephone system.

Nevertheless, an information superhighway which extended into every affluent home in Europe would certainly prove to be an economic motor of some importance. If one assumes that 50 million homes each spent 1000 ECUs per year on such services, the turnover would be 50 billion ECUs, close to half the GDP of Switzerland, and over $11 \%$ of the world telecommunications market of 430 billion ECUs [6].

\section{Can Europe Build Them?}

In the USA, the political will to create a national information superhighway clearly grew out of the long-term networking programme in the research community whose best known results were the ARPANET and the NSFnet. 
Today we hear from our American colleagues of plans to upgrade the NSFnet infrastructure from $45 \mathrm{Mbit} / \mathrm{s}$ to 155 $\mathrm{Mbit} / \mathrm{s}$ or even $622 \mathrm{Mbit} / \mathrm{s}$. In Europe, the best continent-wide Intemet service we have, EuropaNet [7], operates a $2 \mathrm{Mbit} / \mathrm{s}$ backbone and the fastest international pilot so far, BETEL [8], ran at $34 \mathrm{Mbit} / \mathrm{s}$. We clearly lag behind the Americans.

In [4] I gave a list of the barriers to progress in European telematics, and none of them are technical. Many of the issues are economic and political: regulations, tariffs, lack of international competition, conservatism, and lack of political focus. There is also the lack of a solid European scientific computing industry, and hence the lack of the industry-academia collaboration which has been so productive in the USA.

Of course not all the hardware and software technology needed to build an information superhighway exists today, but certainly enough exists to show that there is essentially no technology problem. However, there is one big problem with many of today's Internet services, namely the lack of accounting and billing. Access to most networks forming part of the Internet is normally funded on a global basis by an employer, and most of the services available via the Internet remain free of charge to their individual users. In order for the Internet to evolve fully into the public Information Superhighway, improved accounting and billing facilities will be needed. This will surely not prevent the provision of a whole set of very valuable, but essentially free-of-charge, services being make available for various communities, co-existing with fully commercial services.

Our thoughts about the cost of network services are still too strongly influenced by the idea that bandwidth is a scarce, and therefore expensive, resource. The transmission capacity of optical fibre is already several Gbit/s and wave-division multiplexing will allow more if needed [9]. The ITU has already standardised 9.6 Gbit/s transmission. Even a modest unshielded twisted pair cable of good quality can carry at least $100 \mathrm{Mbit} / \mathrm{s}$ over 100 metres, more than enough for distribution quality HDTV. It is beyond the scope of this paper to attempt a full economic analysis, but clearly the investment in cable plant is far greater than that in transmission equipment and switches, and must be written off over much longer periods. With the advent of optical amplifiers in long distance fibres, only the equipment at each end of the fibre will need to be upgraded to increase the bandwidth. It is not obvious why the cost of supplying megabits of data service to each user over a modern cabling infrastructure should be significantly greater than that of Plain Old Telephone Service. The Ethernet connection to my office certainly cost less to install than the telephone.

What this means is that once a decent cable infrastructure (shared fibre for long distances, individual twisted pair or fibre for short distances) is in place, the actual bandwidth consumed by each user is unimportant within reasonable limits of several $\mathrm{Mbit} / \mathrm{s}$ per user. This will make particularly good sense in an ATM world [10] with properly implemented "available bit rate" services, where each simultaneous transaction will be given a fair share of the currently available bandwidth. When the average load increases, the network providers will have to increase trunk and switch capacity as necessary, but in the future this will rarely involve laying new fibre trunks. As on packet-switching networks or on a public road, this approach will lead to worse response times at busy times of day.

In most countries one pays a fixed fee for road use, usually one that increases with the size of the vehicle. One is frequently required to pay a supplementary toll to use some especially expensive infrastructure such as bridges, tunnels or even, in some countries, the motorways. And, if you return with a load of goods, you will have paid the supplier for them. Thus one could expect to pay a fixed fee for network access, but one that increases with the peak bandwidth available. One could expect to pay a supplementary toll for guaranteed response time, and of course to pay a service provider for the information accessed. However, a road system is only of economic value if its cost to its users is small compared to the value of the goods transported: we expect the cost of driving to the shopping centre to be at most a few percent of our expenditure in the supermarket. In the same way, one should expect the cost of network access to a service to be a small fraction of the cost of the service.

I believe that Europe would benefit by defining tariffing principles where bandwidth is essentially free of charge, but where the suppliers of the network infrastructure are paid on the basis of connectivity (perhaps with premium rates for guaranteed response time), and the suppliers of services are paid by the end user on the basis of the use that is made of their services. Some such fundamental change is needed if Europe is to get out of the current deadlock, where growth in the market for high speed services is completely blocked by tariffs often ten times higher than those in the USA.

Achieving such a change is a political question. The monopoly environment is still too much with us, especially for international connections, and it is effectively stifling any major change in tariff structures. The attempts of 
the European Commission and of European governments to liberalise telematics regulations have been influenced too strongly by advice from representatives of monopoly or quasi-monopoly suppliers. Users, who will need these tools to remain competitive and to ensure Europe's future economic growth, need to speak out more strongly about their requirements, and, above all, to explain them unambiguously to the policticians.

In Europe we have the knowledge and skills to build as many information superhighways as we want or need, but it is scarcely worth making serious proposals until the political and economic deadlock over tariffs has been broken by much more open competition.

\section{Acknowledgements:}

It is a pleasure to acknowledge many stimulating discussions with my colleagues during the preparation of this paper.

\section{References}

1. C.Malamud, Exploring the Internet - a Technical Travelogue, Prentice-Hall, 1992.

2. T.J. Berners-Lee, R. Cailliau, J-F Groff, B. Pollermann, World-Wide Web: The Information Universe, Electronic Networking 2, 52-58 (1992).

3. B. Oakley (ed.), Telematics programme - Mid Term Review Report, Commission of the European Communities, DG XIII, Brussels, July 1993.

4. D.O.Williams, B.E.Carpenter, Data Networking for the European Academic and Research Community: Is It Important?, Electronic Networking, 2, 56-65 (1992).

5. Report of the High Performance Computing and Networking Advisory Committee (Chairman: C.Rubbia), Commission of the European Communities, DG XIII, Brussels, October 1992.

6. Etudes Telecom, 49, 19 (February 1994).

7. S.M. Nielsen, EuropaNet - Contemporary High Speed Networking, Computer Networks and ISDN Systems, 25, S25-S34 (1993).

8. O.H.Martin, Broadband Exchange over Trans-European Links (BETEL), Proc. SMDS Conference, Amsterdam, November 1993.

9. P.E.Green, An All-Optical Computer Network: Lessons Learned, IEEE Network, March 1992, 56-60 (1992).

10. M. De Prycker, Asynchronous Transfer Mode: Solution for Broadband ISDN, Horwood, 1991. 
